Сравнение эффективности препаратов гиалуроновой кислоты с различной молекулярной массой и в сочетании с хондроитин сульфатом в зависимости от стадии остеоартрита коленного сустава

\author{
В.Е. Бялик, М.А. Макаров, Е.И. Бялик, С.А. Макаров, В.А. Нестеренко, М.Р. Нурмухаметов
}

\begin{abstract}
ФГБНУ «Научноисследовательский институт ревматологии им. В. А. Насоновой» 115522, Российская Федерация, Москва, Каширское шоссе, д. $34 \mathrm{a}$
\end{abstract}

V.A. Nasonova Research Institute of Rheumatology 115522, Russian Federation, Moscow, Kashirskoe highway, 34A

Контакты:

Contact:

Поступила: 16.06 .2020
Цель исследования: оценить эффективность внутрисуставных инъекций препаратов гиалуроновой кислоты с различной молекулярной массой и их же в сочетании с хондроитин сульфатом в лечении больных остеоартритом коленного сустава I-III стадии.

Материалы и методы. В отделении травматологии-ортопедии НИИР им. В.А. Насоновой за период с сентября 2017 по июнь 2019 г. внутрисуставные инъекции гиалуроновой кислоты были выполнены 160 пациентам с первичным и посттравматическим остеоартритом коленного сустава I-III стадии. Больные были распределены на 4 группы. В первой $(n=80)$ выполняли внутрисуставные инъекции низкомолекулярной гиалуроновой кислоты, во второй $(n=20)-$ среднемолекулярной гиалуроновой кислоты, в третьей $(n=30)-$ высокомолекулярной гиалуроновой кислоты и в четвертой $(n=30)$ - гиалуроновой кислоты с хондроитин сульфатом. Для низкомолекулярной, высокомолекулярной гиалуроновой кислоты и гиалуроновой кислоты с хондроитин сульфатом курс лечения состоял из 2, для среднемолекулярной гиалуроновой кислоты - из 3 внутрисуставных инъекций. Инъекции выполняли с интервалом в 1 неделю. Для оценки результатов определяли интенсивность боли по визуальной аналоговой шкале и общий счет KOOS до начала лечения, через 1 , 3 и 6 мес. после курса внутрисуставных инъекций гиалуроновой кислоты.

Результаты. Максимальное снижение боли на I стадии остеоартрита коленного сустава отмечали через 3 мес. после курса внутрисуставных инъекций. При этом в 84,3\% случаев улучшение было выявлено через 1 мес., у $71,1 \%$ пациентов оно сохранялось до конца исследования. Эффективность разных препаратов гчюиалуроновой кислоты на I стадии остеоартрита коленного сустава была сопоставима. На II стадии остеоартрита коленного сустава улучшение через 1 мес. после курса внутрисуставных инъекций гиалуроновой кислоты наблюдалось в 53,9\% случаев. В группах низкомолекулярной, среднемолекулярной и гиалуроновой кислоты с хондроитин сульфатом оно сохранялось в течение 3 мес., а в группе высокомолекулярной гиалуроновой кислоты после 1 мес. эффект утрачивался. Через 3 мес. лучшие результаты отмечались после введения гиалуроновой кислоты с хондроитин сульфатом; через 6 мес. эффективность лечения была сопоставима, достигнутое улучшение сохранялось у $30,8 \%$ пациентов. При ІІІ стадии остеоартрита коленного сустава эффективность исследуемых препаратов была сопоставимой. Улучшение через 1 мес. после курса лечения было достигнуто у 40,6\% больных. Через 3 мес. оно сохранялось в 18,8\%, а через 6 мес. - в 15,7\% случаев. Выводы. Внутрисуставное введение препаратов гиалуроновой кислоты на I стадии остеоартрита коленного сустава - высокоэффективный метод консервативного лечения, позволяющий добиться купирования боли и улучшения функции сустава на срок до 6 мес. На ІІ стадии остеоартрита коленного сустава эффект сохраняется до 3 мес. после внутрисуставных инъекций низкомолекурярной и среднемолекулярной гиалуроновой кислоты, а также данной кислоты с хондроитин сульфатом. После внутрисуставных инъекций высокомолекулярной гиалуроновой кислоты снижение интенсивности боли сохраняется в течение 1 мес. Применение препаратов гиалуроновой кислоты на III стадии остеоартрита коленного сустава способствует краткосрочному облегчению симптомов остеоартрита.

Ключевые слова: остеоартрит, коленный сустав, гиалуроновая кислота, хондроитин сульфат, эффективность Для цитирования: Бялик В. Е., Макаров М.А., Бялик Е.И., Макаров С.А., Нестеренко В. А., Нурмухаметов М.Р. Сравнение эффективности препаратов гиалуроновой кислоты с различной молекулярной массой и в сочетании с хондроитин сульфатом в зависимости от стадии остеоартрита коленного сустава. Научнопрактическая ревматология.2020;58(5):560-569.

\section{COMPARISON OF THE EFFECTIVENESS OF HYALURONIC ACID PREPARATIONS WITH DIFFERENT MOLECULAR WEIGHTS AND IN COMBINATION WITH CHONDROITIN SULFATE DEPENDING ON THE STAGE OF OSTEOARTHRITIS OF THE KNEE JOINT}

Vladislav E. Bialik*, Maksim A. Makarov, Evgenii I. Bialik, Sergey A. Makarov, Vadim A. Nesterenko, Maksim R. Nurmukhametov

Aim: to evaluate the effectiveness of hyaluronic acid (HA) preparations with different molecular weights and in combination with chondroitin sulfate (HS) for intra-articular (IA) injections in the treatment of patients with stage I-III knee OA.

Subjects and methods. IA HA injections were performed 160 patients with primary and post-traumatic knee OA of the I-III stages at the department of traumatology-orthopedics, V.A. Nasonova Research Institute of Rheumatology for the period from September 2017 to June 2019. Patients were divided into 4 groups. Group 1 consisted of 80 patients treated with low molecular weight (LMW) HA, group 2-20 patients treated with medium molecular weight (MMW) HA, group 3-30 patients treated with high molecular weight (HMW) HA, and group 4-30 patients who were intraar- 
ticular introduced HA with HS. The course of IA injections was 2 for LMW, HMW, and HA with HS, and 3 for MMW HA. Injections were performed with an interval of 1 week. To evaluate the results of treatment, we studied the intensity of pain according to VAS and the total score of KOOS before treatment and on follow-up examinations 1, 3 and 6 months after the course of IA HA injections.

Results. The maximum reduction in pain with IA HA injections at stage I of knee OA occurred by 3 months after the course of treatment. Moreover, improvement was detected by 1 month in $84.3 \%$ of cases, and remained until the end of the study in $71.1 \%$ of patients. All HA preparations used in stage I of knee OA were effective. At stage II of the knee OA after 3 months after the course of IA HA, different efficiencies of HA preparations were revealed. So, in the groups of LMW, MMW and HA with HS, the improvement persisted up to 3 months, and in the group of HMW HA - up to 1 month. After 3 months, the best results were shown by HA with HS, by 6 months the results were comparable. IA HA injections at the II stage of knee OA led to good and excellent results 1 month after the course of treatment in $53.9 \%$ of cases, but by the end of the study, improvement remained in only $30.8 \%$ of patients. In the case of the use of HA in stage III of the knee OA, the effectiveness of the studied drugs was comparable, and the maximum improvement was achieved by 1 month. The positive effect of IA HA injections in patients with stage III of the knee OA one month after the course of treatment was obtained in $40.6 \%$ of cases, by 3 months it decreased to $18.8 \%$, and by 6 months - to $15.7 \%$ of patients.

Conclusions. IA injections of HA at stage I of the knee OA is a highly effective method of conservative treatment, which allows to relieve pain and improve the condition of the knee joint for a period of 6 months or more. The use of HA preparations at stage II of the knee OA allows reducing pain up to 3 months with IA injections of LMW and MMW HA, as well as HA with HS. HMW HA helps reduce pain intensity for a period of 1 month. The use of HA preparations in stage III of the knee OA leads to a short-term relief of symptoms of OA.

Keywords: osteoarthritis, knee joint, hyaluronic acid, chondroitin sulfate, effectiveness

For citation: Bialik V.E., Makarov M.A., Bialik E.I., Makarov S.A., Nesterenko V.A., Nurmukhametov M.R. Comparison of the Effectiveness of Hyaluronic Acid Preparations with Different Molecular Weights and in Combination with Chondroitin Sulfate Depending on the Stage of Osteoarthritis of the Knee Joint. Nauchno-Prakticheskaya Revmatologiya=Rheumatology Science and Practice 2020;58(5):560-569 (In Russ.). doi: 10.47360/1995-4484-2020-560-569

\section{Введение}

Остеоартрит (ОА) является самым распространенным заболеванием опорно-двигательного аппарата, характеризуется хронической болью и нарушением функции суставов [1], занимает четвертое место среди причин инвалидности [2]. Распространенность ОА в мире постоянно растет, что связано с увеличением продолжительности жизни, старением населения и увеличением числа людей, страдающих ожирением [1]. Наиболее часто ОА поражает коленный сустав (KC), а частота симптоматического ОА $\mathrm{KC}$ в общей популяции достигает $25 \%$ [3].

Для лечения ОА КС в настоящее время применяют нефармакологические и фармакологические методы, включая локальную инъекционную терапию [1, 4-7]. В современных рекомендациях по фармакотерапии ОА наибольшее внимание уделено анальгетикам, в первую очередь назначению нестероидных противовоспалительных препаратов (НПВП) и парацетамола [8]. Такая терапия нередко сопряжена с развитием неблагоприятных реакций [9].

Для уменьшения потребности в анальгетиках при OA КС широко используются внутрисуставные инъекции (ВИ) препаратов гиалуроновой кислоты (ГлК), механизм действия которой зависит от молекулярной массы. Эффект низко- (НM) и среднемолекулярной (CM) ГлК обусловлен ее взаимодействием с CD-44-рецепторами хондроцитов, проникновением через синовиальную мембрану и стимуляцией выработки эндогенной высокомолекулярной (ВМ) ГлК и, как следствие, улучшением механических свойств синовиальной жидкости. С увеличением молекулярной массы препаратов ГлК снижается их способность к взаимодействию с CD-44-рецепторами. ВМ ГлК улучшает скольжение суставных поверхностей, снижая трение между ними. ГлК также способствует снижению концентрации провоспалительных медиаторов и стимулирует синтез протеогликанов [10-16]. Препараты ГлК, применяемые в ревматологии и ортопедии, различаются молекулярным весом, наличием поперечных связей, концентрацией, вязкостью, объемом вводимой жидкости, режимом дозирования, наличием дополнительных компонентов [17]. Крупные исследования, систематические обзоры и метаанализы приводят противоречивые результаты применения препаратов ГлК для лечения ОА [18-24]. Отсутствует единое мнение о целесообразности их использования. Так, Американская академия хирургов-ортопедов (AAOS) и Национальный институт здравоохранения и усовершенствования медицинского обслуживания (NICE) применение ГлК не рекомендуют. Европейская антиревматическая лига (EULAR) рекомендует использовать ГлК по узким показаниям. Американская коллегия ревматологов (ACR) условно не рекомендует применять ВИ препаратов ГлК [25]. Международное общество исследований OA (OARSI) условно рекомендует использовать ГлК у всех пациентов с ОА [26]. Ассоциация ревматологов России (АРP) рекомендует применение ГлК при неэффективности предшествующей немедикаментозной терапии и НПВП [1]. В настоящее время наиболее изученными препаратами ГлК являются синвиск (гилан GF-20; США) и гиалган (Италия) [17]. Однако для большинства присутствующих на рынке препаратов ГлК нет научных данных, подтверждающих их эффективность при ОА.

Целью нашего исследования стала оценка эффективности препаратов ГлК с различной молекулярной массой и комбинации ГлК с хондроитин сульфатом (ХC) для внутрисуставного введения в лечении больных ОА КС I-III стадии.

\section{Материалы и методы}

В отделении травматологии-ортопедии ФГБНУ «НИИР им. В.А. Насоновой» за период с сентября 2017 по июнь 2019 г. ВИ препаратов ГлК были выполнены 160 больным. Среди них преобладали женщины, соотношение 2,5:1. Средний возраст пациентов составил

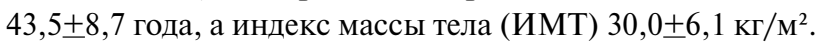

Критерии включения: подписанное информированное согласие на участие в исследовании, интенсивность боли в КС, по визуальной аналоговой шкале (ВАШ) $>40$ мм; диагноз ОА КС, соответствующий критериям $\mathrm{ACR}$, рентгенологические признаки OA KC I-III стадии по классификации Kellgren-Lawrence. 
Критерии исключения: клинические признаки синовита КС; остеонекроз мыщелков бедренной и/или большеберцовой костей; предшествовавшее введение глюкокортикоидов в КС менее чем за 6 мес. до включения в исследование; внутрисуставное введение других препаратов в КС в течение 6 нед. до начала исследования; прием симптоматических препаратов замедленного действия, завершенный менее чем за 3 мес. до начала исследования; кожное заболевание области предполагаемой инъекции; вторичный OA на фоне инфекционного артрита, генетических и метаболических заболеваний; боль в КС, вызванная другими причинами (синдром Зудека, внутрисуставная опухоль, виллонодулярный синовит).

В исследовании приняли участие пациенты с первичным и посттравматическим ОА (ПТОА) КС. Рентгенологическую стадию ОА КС определяли в соответствии с классификацией Kellgren-Lawrence по рентгенограммам КС в прямой проекции (рис. 1).

У 120 (75\%) больных был первичный ОА КС и у $25 \%$ ПТОА. У 37 (23,1\%) пациентов была I, у 91 (56,8\%) - II и у $32(20,1 \%)$ - III стадия ОА КС.

Сформированы 4 группы больных. В первой $(n=80)$ для введения в КС использовали НМ ГлК (гексадециламидное производное ГлК с молекулярной массой 500730 кДа), во второй $(n=20)-$ СМ ГлК (1500-2000 кДа), в третьей $(n=30)$ - ВМ ГлК $(3500$ кДа) и в четвертой $(n=30)$ - ВМ ГлК с ХС (натрия гиалуронат 60 мг/3 мл и хондроитин сульфат натрия 90 мг/3 мл). Курс ВИ для НМ, ВМ ГлК и ГлК с ХС состоял из 2 инъекций, для СМ ГлК - из 3. ВИ выполняли с интервалом в 1 нед.

Для оценки эффективности лечения определяли интенсивность боли в КС по визуальной аналоговой шкале (ВАШ). Кроме того, использовали опросник KOOS (Knee injury and Osteoarthritis Outcome Score), позволяющий регистрировать боль, функцию КС в повседневной жизни, во время отдыха и занятий спортом и качество жизни. Осмотр больных и заполнение опросников осуществляли до начала лечения, через 1, 3 и 6 мес. после курса ВИ. При оценке результатов лечения основное внимание уделяли изменению интенсивности боли, поскольку она является главной причиной обращения больного к травматологу-ортопеду и может служить интегральным показателем эффективности ВИ ГлК. При снижении интенсивности боли по ВАШ до 0-19 мм результат оценивали как отличный, 20-39 мм - хороший, 40-59 мм (боль становилась слабее, чем до курса ВИ, либо, как минимум, не усиливалась) - удовлетворительный. Критерием неудовлетворительного результата лечения было усиление боли по ВАШ выше исходных значений либо интенсивность боли $\geq 60$ мм. Также оценивали общий счет KOOS, который может варьировать от 0 до 100. Его уменьшение свидетельствует об ухудшении, увеличение - об улучшении состояния КС.

Статистическую обработку полученных данных проводили на персональном компьютере с использованием приложения Microsoft Excel и пакета статистического анализа данных Statistica 12 for Windows (StatSoft Inc., USA). Количественные переменные описывали при помощи медианы, 25-го и 75-го перцентилей. Качественные показатели описывали абсолютными и относительными частотами (процентами). Анализ сопоставимости групп осуществляли при помощи непараметрического критерия Краскела Уоллиса. Сравнение данных в динамике проводили при помощи непараметрического критерия Вилкоксона. Сравнительный анализ результатов между исследуемыми группами проводили при помощи критерия Пирсона $\chi^{2}$ Различия считали достоверными при $p<0,05$.

\section{Результаты}

Распределение пациентов по стадиям ОА КС в сравниваемых группах было неравномерным и подробно отражено на рисунке 2.

В группе НМ ГлК у 36,3\% больных была I, у 51,2\% II, у 12,5\% - III стадия ОА КС, в группе СМ ГлК - у 0, 70 и $30 \%$, в группе ВМ ГлК - у 3,3, 73,3 и 23,4\%, в группе ГлК с ХС - у 23,4, 46,6 и 30,0\% соответственно.

Характеристика пациентов с I стадией ОА КС представлена в таблице 1.

В группах НМ ГлК и ГлК с ХC пациенты с I стадией болезни до лечения были сопоставимы по возрасту, ИМТ, интенсивности боли по ВАШ и общему счету KOOS. Динамика боли по ВАШ у этих больных отражена на рисунке 3 .

Пациенты с I стадией OA KC достигали максимального улучшения через 3 мес. после лечения, позднее появлялась тенденция к незначительному усилению боли. В группе НМ ГлК уже через 1 мес. после ВИ было отмечено статистически значимое $(p=0,000024)$ снижение боли по ВАШ с уменьшением ее медианы с 50 [40; 60] до $20[10 ; 30]$ мм. Данное $\square$ І стадия ОА КС ( $n=37)$

$\square$ ІІ стадия ОА КС ( $n=91)$

III стадия ОА КС ( $n=32)$
Рис. 1. Диагнозы и стадии ОА КС у пациентов, включенных в исследование

$\square$ Посттравматический остеоартрит ( $n=36)$

Таблица 1. Характеристика пациентов с I стадией ОА КС, медиана [25; 75 перцентили]

\begin{tabular}{lllll}
\hline Препарат & Возраст (годы) & ИМТ (кг/м²) & Боль по ВАШ (мм) & Общий счет КОоS (баллы) \\
\hline НМ ГлК $(n=29)$ & $42[30 ; 49]$ & $26,7[23,8 ; 28,7]$ & $50[40,0 ; 60,0]$ & $67,9[56,2 ; 78,6]$ \\
\hline ГлК с ХС $(n=7)$ & $34[29,5 ; 39,0]$ & $26,9[23,1 ; 28,1]$ & $45[40,0 ; 50,0]$ & $63,5[59,0 ; 70,5]$ \\
\hline
\end{tabular}


улучшение сохранялось вплоть до окончания исследования. У единственной пациентки с I стадией ОА КС, получавшей ВМ ГлК, через 1 мес. было отмечено снижение боли по ВАШ на 30 мм. Через 3 мес. боль пациентку не беспокоила, а через 6 мес. ее интенсивность не превышала 10 мм. Применение ГлК с ХС при I стадии ОА КС сопровождалось статистически значимым снижением боли $(p=0,017)$ по ВАШ через 1 мес. после ВИ. Ее медиана уменьшилась с 45 [40; 50] до 20 [15; 50] мм. Через 3 мес. она составляла 10 [5; 30] мм, а через 6 мес. - 15 [10; 25] мм.

У всех пациентов с I стадией OA КС было выявлено улучшение общего счета KOOS, которое сохранялось до конца исследования (рис. 4).

В группе НМ ГлК в течение 1 мес. после ВИ происходило статистически значимое $(p=0,0005)$, стойкое повышение общего счета KOOS. Его медиана увеличилась с 67,9 [56,2; 78,6] до 82,3 [70,2; 86,0] балла и в конце наблюдения составляла $82,3[62,0 ; 94,4]$ балла $(p=0,000029)$. У больной, которой вводили ВМ ГлК, общий счет KOOS через 1 мес. увеличился с 68,9 до 92,3 балла, через 3 мес. - до 96,0, через 6 мес. составлял 92,3 балла. В группе пациентов, получавших ГлК с ХС, в течение первого месяца наблюдали статистически значимое повышение $(p=0,011)$ общего счета KOOS, медиана которого увеличилась с 63,5 [59,0; 70,5] до 80,7 [71,0; 90,3]. Через 3 мес. она составляла $84,1[77,0 ; 92,1]$ и через 6 мес. - 82,2 [74,5; 89,3] балла.

В целом через 1 мес. после ВИ ГлК отличные и хорошие результаты при I стадии ОА КС были получены у $32(84,3 \%)$ из 38 пациентов. Через 3 мес. - у 29 (76,4\%), а через 6 мес. у 27 (71,2\%) (рис. 5).

Единственный пациент в группе ВМ ГлК имел отличный результат на всем протяжении исследования. В группе НМ ГлК через 1 мес. отличные и хорошие результаты были зафиксированы в $86,3 \%$ случаев, через 3 мес. - в 68,9\%, через 6 мес.в $65,6 \%$. В группе ГлК с ХС соответственно в 71,5, 100 и 86,0\% случаев, однако эти различия не были статистически значимыми.

Характеристика пациентов c II стадией OA КС представлена в таблице 2.

Пациенты с II стадией OA КС во всех группах были сопоставимы по всем представленным параметрам. В группе ГлК с ХС отмечалась несколько менее интенсивная боль в КС, однако это различие не достигало статистической значимости $(p=0,06)$.

Изменение боли по ВАШ у пациентов с II стадией ОА КС представлено на рисунке 6.

При ІІ стадии ОА КС максимальное уменьшение боли по ВАШ после ВИ препаратов НМ и ВМ ГлК отмечали через 1 и 3 мес. при использовании СМ ГлК и ГлК с ХС. Через 1 мес. после введения НМ ГлК было достигнуто значимое

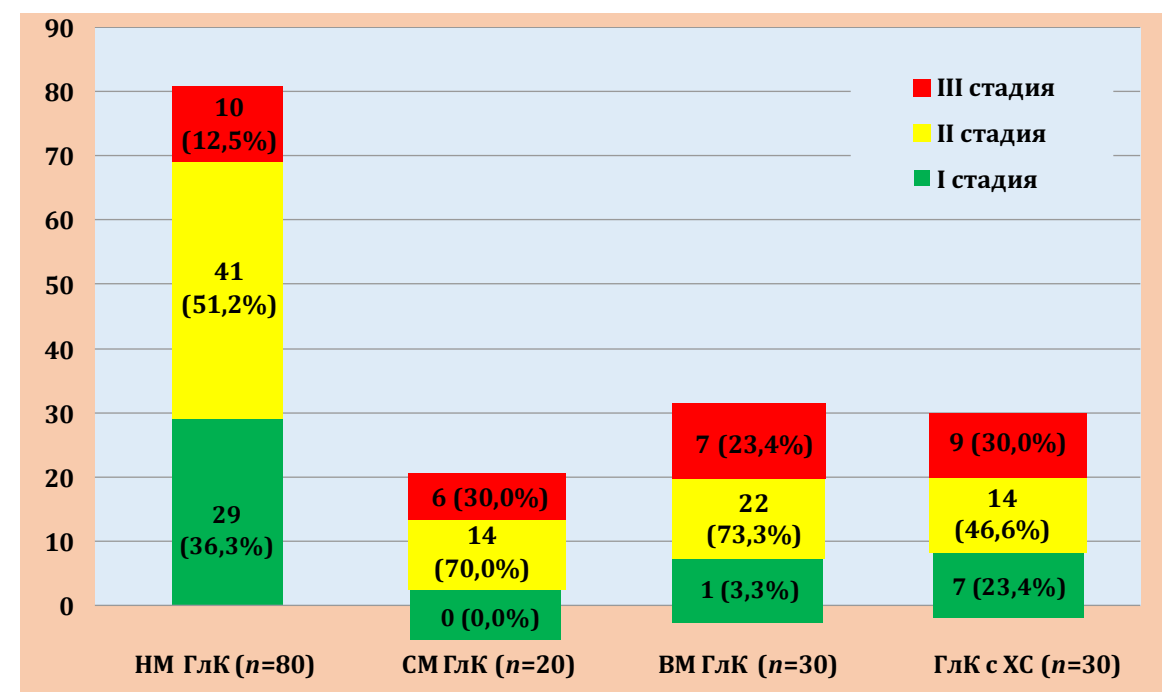

Рис. 2. Распределение больных по стадиям ОА в сравниваемых группах

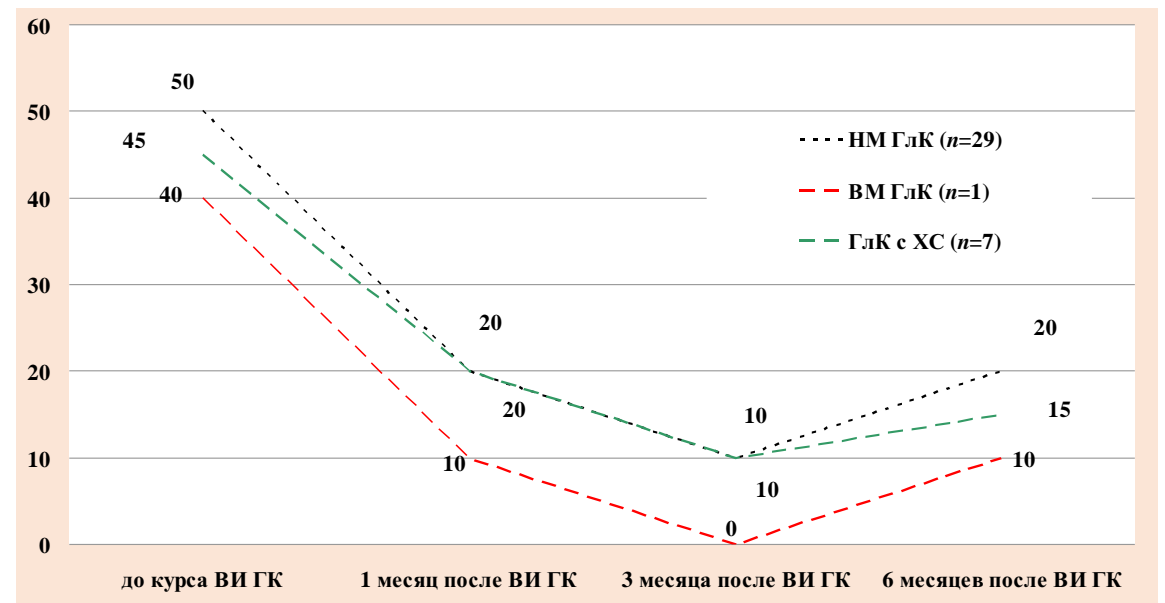

Рис. 3. Динамика боли по ВАШ у пациентов с I стадией ОА КС

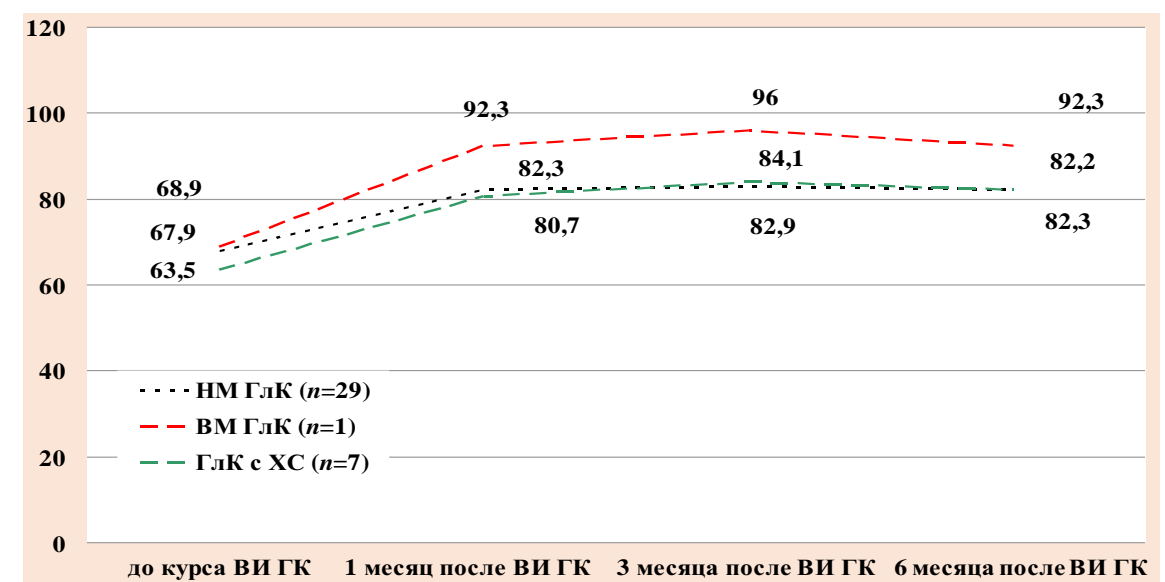

Рис. 4. Изменение общего счета KOOS у пациентов с I стадией OA KC 
\% пациентов с улучшением

120

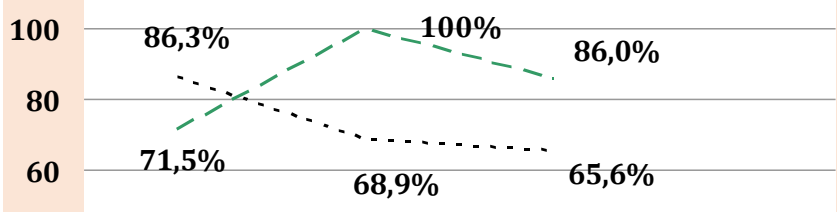

40

20

$\mathbf{0}$

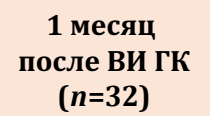

1 месяц
после ВИ ГК

$(n=32)$

A
\% пациентов с улучшением (всего)

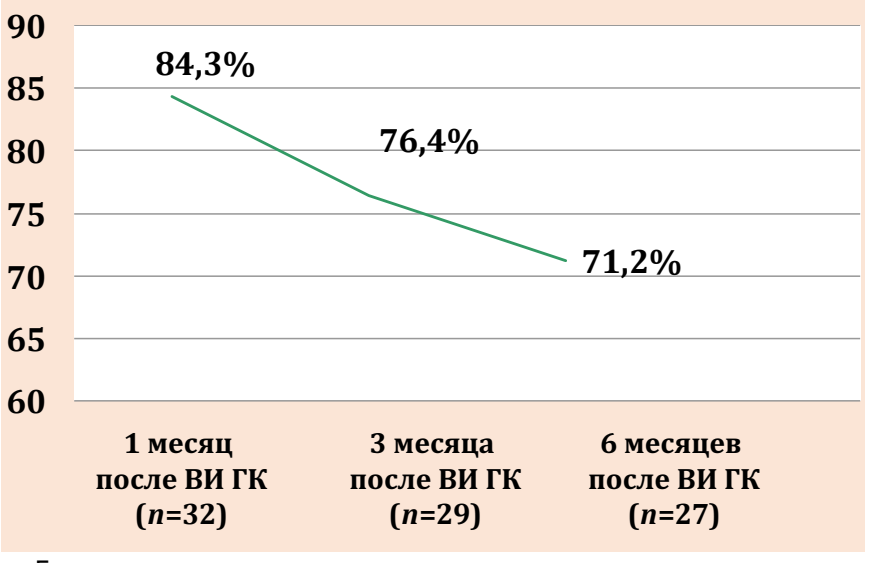

Б

Рис. 5. Результаты ВИ ГлК у пациентов с I стадией ОА КС: А - изменение числа больных с улучшением в сравниваемых группах; Б - изменение общего числа больных с улучшением

Таблица 2. Характеристика пациентов с II стадией ОА КС, медиана [25; 75 перцентили]

\begin{tabular}{lllll}
\hline Препарат & Возраст (годы) & ИМТ (кг/м²) & Боль по ВАШ (мм) & Общий счет КоОS (баллы) \\
\hline НМ ГлК $(n=41)$ & $60[54,0 ; 70,0]$ & $30,5[28,3 ; 34,0]$ & $50[50,0 ; 60,0]$ & $50[44,6 ; 57,5]$ \\
\hline СМ ГлК $(n=14)$ & $62,5[48,0 ; 67,0]$ & $31,9[27,5 ; 35,3]$ & $60[40,0 ; 70,0]$ & $56,8[39,9 ; 77,4]$ \\
\hline ВМ ГлК $(n=22)$ & $61,5[57,0 ; 70,0]$ & $28,5[26,0 ; 30,5]$ & $60[50,0 ; 65,0]$ & $56,5[47,5 ; 64,9]$ \\
\hline ГлК с ХС $(n=14)$ & $55[49,0 ; 69,0]$ & $29,2[26,2 ; 31,7]$ & $50[40,0 ; 55,0]$ & $52[48,0 ; 66,0]$ \\
\hline
\end{tabular}

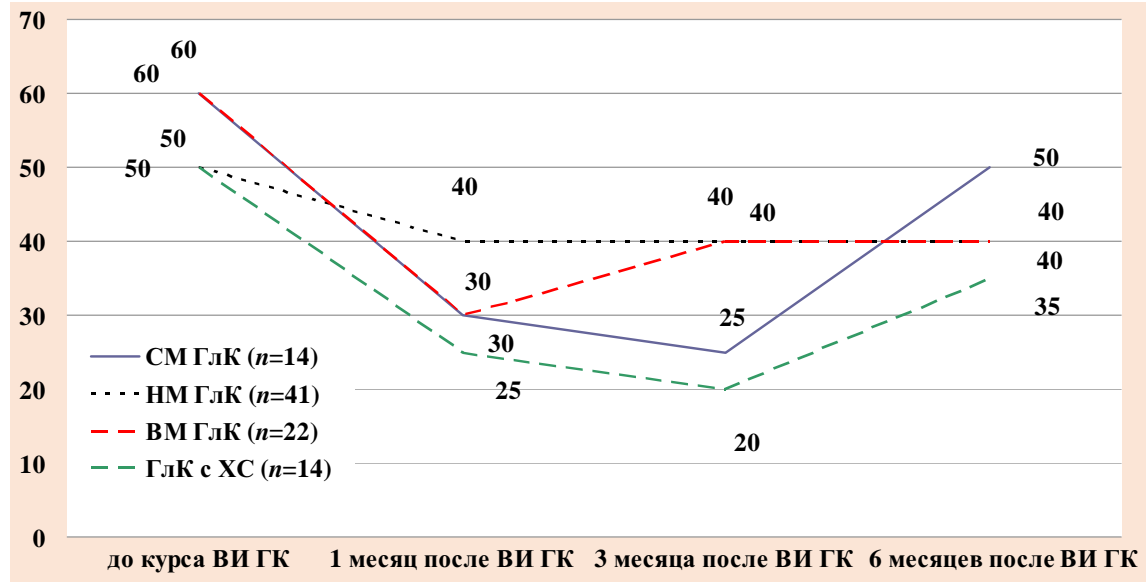

Рис. 6. Изменение боли по ВАШ у пациентов с II стадией ОА КС

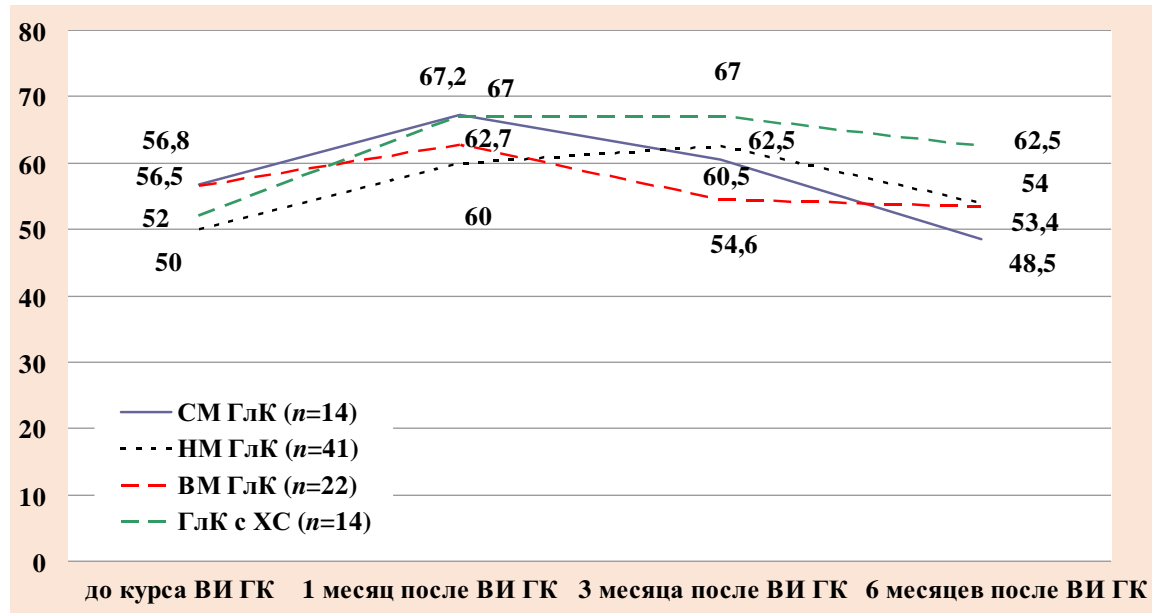

Рис. 7. Изменение общего счета KOOS у пациентов с II стадией OA KC уменьшение интенсивности боли, ее медиана снизилась с 50 [50;60] до 40 $[20 ; 50]$ мм $(p=0,000003)$. В дальнейшем достигнутое улучшение сохранялось, через 6 мес. медиана боли составляла 40 [30; 50] мм. В группе СМ ГлК медиана боли по ВАШ через 1 мес. после ВИ уменьшилась с 60 [40; 70] до $30[10 ; 50]$ мм $(p=0,004)$. Через 3 мес. она составляла 25 [10; 50] мм, через 6 мес. - 50 [10; 70] мм. При использовании ВМ ГлК через 1 мес. после ВИ отмечалось существенное улучшение, медиана боли уменьшилась с 60 [50; 65] до 30 [20; 40] мм. Через 3 и 6 мес. она составляла 40 [30; 50] мм, значимых различий по сравнению с исходными данными не было. Через 1 мес. после ВИ ГлК с ХС медиана боли по ВАШ уменьшилась с 50 [40; 55] до 25 [15; 30] мм $(p=0,000982)$. Через 3 мес. она составляла 20 [10; 30] мм, через 6 мес. 35 [30; 40] мм, к концу наблюдения интенсивность боли была значимо ниже, чем до курса ВИ ГлК, $p=0,007$.

У пациентов со II стадией ОА КС при использовании СМ, ВМ ГлК и ГлК с ХС максимальное увеличение общего счета KOOS наблюдали через 1 мес., после ВИ НМ ГлК - через 3 мес. Положительная динамика данного показателя после 
внутрисуставного введения СМ и ВМ ГлК была нестойкой, и уже через 3 мес. значения общего счета KOOS были сопоставимы с исходными. В то же время после ВИ НМ ГлК и ГлК с ХС статистически значимое повышение общего счета KOOS сохранялось в течение 6 мес.

У пациентов в группе НM ГлК общий счет KOOS через 1 мес. значимо увеличился, его медиана возросла с 50 $[44,6 ; 57,5]$ до $60[46,0 ; 76,8]$ баллов, $p=0,00014$ (рис. 7). Через 3 мес. она составляла 62,5 [48,0; 68,0], а через 6 мес. $54,0[47,9 ; 68,4]$ балла. Несмотря на такое снижение, общий счет KOOS оставался значимо выше, чем до лечения $(p=0,007)$. У пациентов со II стадией ОА КС, получавших CM ГлК, изменения общего счета KOOS не достигали статистической значимости. В группе ВМ ГлК при II стадии ОА КС через 1 мес. после ВИ отмечали значимое повышение общего счета KOOS, его медиана возросла с 56,5 [47,5; $64,9]$ до 62,7 [51,8; 70,2] балла $(p=0,02)$. Позднее наблюдали ее постепенное снижение. Через 3 мес. она составляла 54,6 $[43,9 ; 70,8]$, а через 6 мес. - 53,4 [45,1; 66,0]. Через 1 мес. после курса ВИ ГлК с ХC общий счет KOOS значимо повысился, его медиана возросла с 52,0 [48,0; 66,0] до 67,0 [57,7; $78,0]$ балла $(p=0,013)$. Через 3 мес. она составляла 67,0 [61,0; $75,0]$, через 6 мес. $-62,5$ [54,0; 72,0] балла, что было значимо выше, чем до лечения $(p=0,011)$.

Результаты оценки эффективности лечения при ОА КС II стадии представлены на рисунке 8.

Через 1 мес. после курса ВИ ГлК у пациентов со II стадией ОА КС отличные и хорошие результаты лечения были зафиксированы в $49(53,9 \%)$ случаях. Через 3 мес. число больных с улучшением уменьшилось до 44 (48,4\%), через 6 мес. - до $28(30,8 \%)$.

Результаты оценки эффективности исследуемых препаратов через 1 мес. были сопоставимы. Через 3 мес. в группе ГлК с ХС они были значимо лучше, чем в группах СМ ГлК $(p=0,02)$, НМ ГлК $(p=0,0003)$ и ВМ ГлК $(p=0,00004)$.
Через 6 мес. результаты оценки эффективности исследуемых препаратов существенно не различались.

В группе НМ ГлК отличные и хорошие результаты через 1 мес. после курса лечения наблюдались в 41,4\% случаев. Данный результат сохранялся и через 3 мес. После 6 мес. доля таких больных уменьшилась до 26,7\%. Через 1 мес. после ВИ СМ и ВМ ГлК было получено соответственно 57,0 и 59,0\% отличных и хороших результатов. После 3 мес. этот эффект сохранялся у 57,2\% пациентов, получавших СМ ГлК, и у $27,1 \%$ в группе ВМ ГлК. Через 6 мес. после курса ВИ улучшение сохранялось у $29,0 \%$ пациентов в группе СМ ГлК и у $27,1 \%$ в группе ВМ ГлК. Внутрисуставное введение ГлК с ХС при II стадии ОА КС через 1 мес. позволило добиться 78,5\% отличных и хороших результатов. Через 3 мес. число отличных и хороших результатов увеличилось до 92,8\%. Через 6 мес. улучшение сохранялось в $50 \%$ случаев.

Характеристика пациентов с III стадией ОА КС представлена в таблице 3 .

Пациенты с III стадией ОА КС во всех группах были сопоставимы по всем исследуемым показателям, кроме возраста. В группе ГлК с ХС пациенты были значительно моложе, чем в группах НМ ГлК $(p=0,022)$ и СМ ГлК $(p=0,03)$.

Изменение боли по ВАШ у пациентов с III стадией ОА КС представлено на рисунке 9.

При III стадии ОА КС максимальное снижение интенсивности боли было достигнуто через 1 мес. после внутрисуставного введения препаратов ГлК, после чего боль вновь усиливалась.

Через 1 мес. после ВИ НМ ГлК отмечали значимое снижение боли по ВАШ и уменьшение ее медианы с 60 [60; $70]$ до $40[30 ; 60]$ мм $(p=0,017)$. Через 3 мес. она составляла 50 [40; 60] мм, через 6 мес. - 60 [40; 70] мм. После ВИ СМ ГлК медиана боли через 1 мес. снижалась с 67,5 [60; 80]
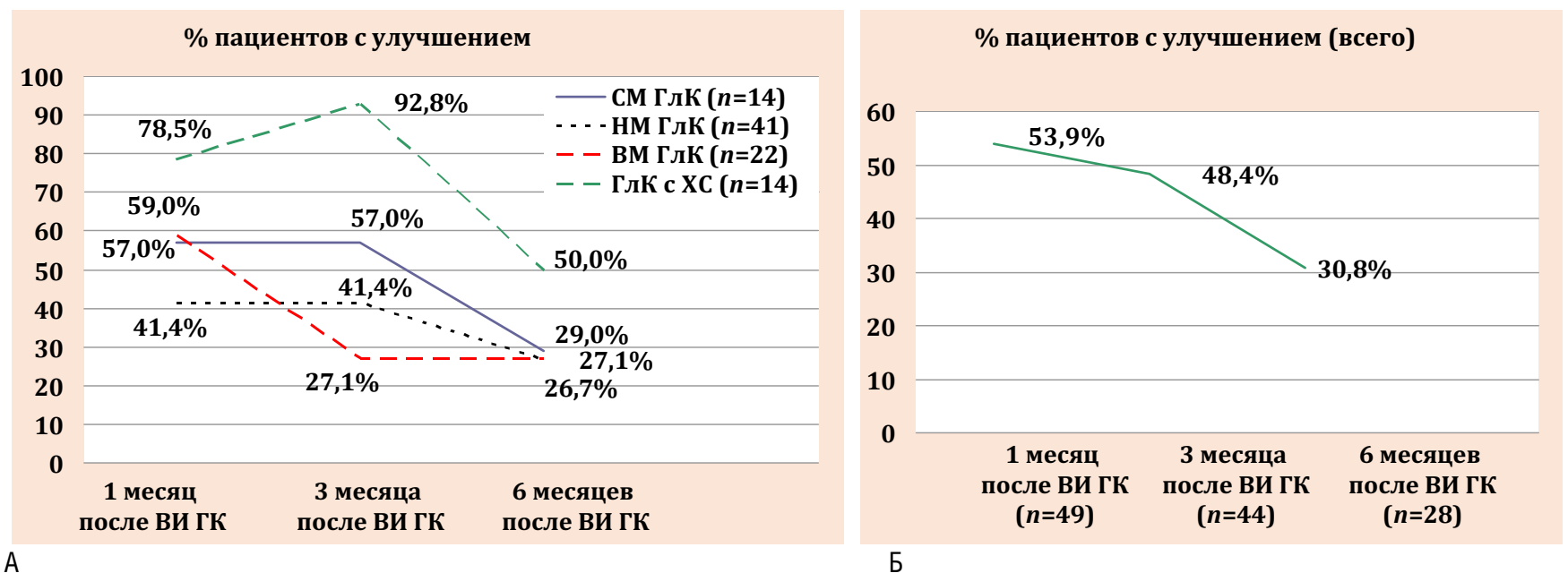

A

Рис. 8. Результаты ВИ ГлК у пациентов с II стадией ОА КС: А - изменение числа больных с улучшением в сравниваемых группах, Б - изменение общего числа больных с улучшением

Таблица 3. Характеристика пациентов с III стадией ОА КС, медиана [25; 75 перцентили]

\begin{tabular}{lllll}
\hline Препарат & Возраст (годы) & ИМт (кг/м²) & Боль по ВАШ (мм) & 0бщий счет КоОS (баллы) \\
\hline НМ ГлК $(n=10)$ & $69[67,0 ; 73,0]$ & $31,3[25,2 ; 34,0]$ & $60[60,0 ; 70,0]$ & $41,2[31,0 ; 63,1]$ \\
\hline СМ ГлК $(n=6)$ & $77[61,0 ; 85,0]$ & $27,3[24,8 ; 39,0]$ & $67,5[60,0 ; 80,0]$ & $46,1[43,3 ; 51,2]$ \\
\hline ВМ ГлК $(n=7)$ & $64[58,0 ; 67,0]$ & $35,2[33,3 ; 40,8]$ & $40[50,0 ; 70,0]$ & $34,5[31,2 ; 42,7]$ \\
\hline ГлК с ХС $(n=9)$ & $61[54,5 ; 64,5]$ & $34,6[31,6 ; 42,7]$ & $50[50,0 ; 60,0]$ & $49,5[48,5 ; 61,5]$ \\
\hline
\end{tabular}


до 50 [30; 50] мм $(p=0,027)$. Через 3 и 6 мес. она составляла 60 [50; 90] мм. У пациентов, получавших ВМ ГлК, интенсивность боли существенно не менялась. После введения ГлК с ХС медиана боли через 1 мес. уменьшалась с 50 [50; $60]$ до $35[30 ; 45]$ мм $(p=0,011)$. Позднее статистически значимые различия по сравнению с исходным уровнем утрачивались. Через 3 мес. медиана боли составляла 35 [30; 40] мм, через 6 мес. -40 [35; 50] мм.
Изменение общего счета KOOS представлено на рисунке 10 .

Медиана общего счета KOOS через 1 мес. после ВИ увеличилась с 49,5 [48,5; 61,5] до 66,0 [55,1; 68,5] балла, через 3 мес. она снизилась до 65,0 [54,0; 68,5], через 6 мес. до 60,3 [54,0; 64,0] балла.

В группе НМ ГлК при III стадии ОА КС изменение данного показателя не достигало статистической значи-
мости. После ВИ СМ ГлК изменемости. После ВИ СМ ГлК измене-
ния общего счета KOOS в течение 3 мес. были незначительными, после чего он резко снижался и через 6 мес. был значимо ниже исходного уровня $(p=0,046)$. После введения ВМ ГлК общий счет KOOS несколько снижался, но эта динамика не достигала статистической значимости $p=0,23$. После ВИ ГлК с ХС отмечалось значимое повышение общего счета KOOS через 1 и 3 мес. $(p=0,011)$, но через 6 мес. оно теряло статистическую значимость.

Результаты оценки эффективности лечения пациентов с ОА КС III стадии представлены на рисунке 11.

Отличных результатов через 1 мес. после ВИ ГлК у больных с ІІІ стадией ОА КС не было. Хороший результат был достигнут у $13(40,6 \%)$ пациентов. Через 3 мес. улучшение сохранялось у $6(18,8 \%)$, а через $6-$ у $5(15,7 \%)$ из них.

Применение НМ ГлК через 1 мес. после курса лечения дало возможность получить хороший результат в 4 (40\%) случаях, однако через 3 мес. пациентов с улучшением в данной группе не осталось. У 1 больного через 6 мес. после ВИ наблюдалось улучшение, но связать его с применением НМ ГлК сложно. При ВИ СМ ГлК хороший результат через 1 мес. был получен в $2(33,3 \%)$

Рис. 10. Изменение общего счета KOOS у пациентов с III стадией OA KC
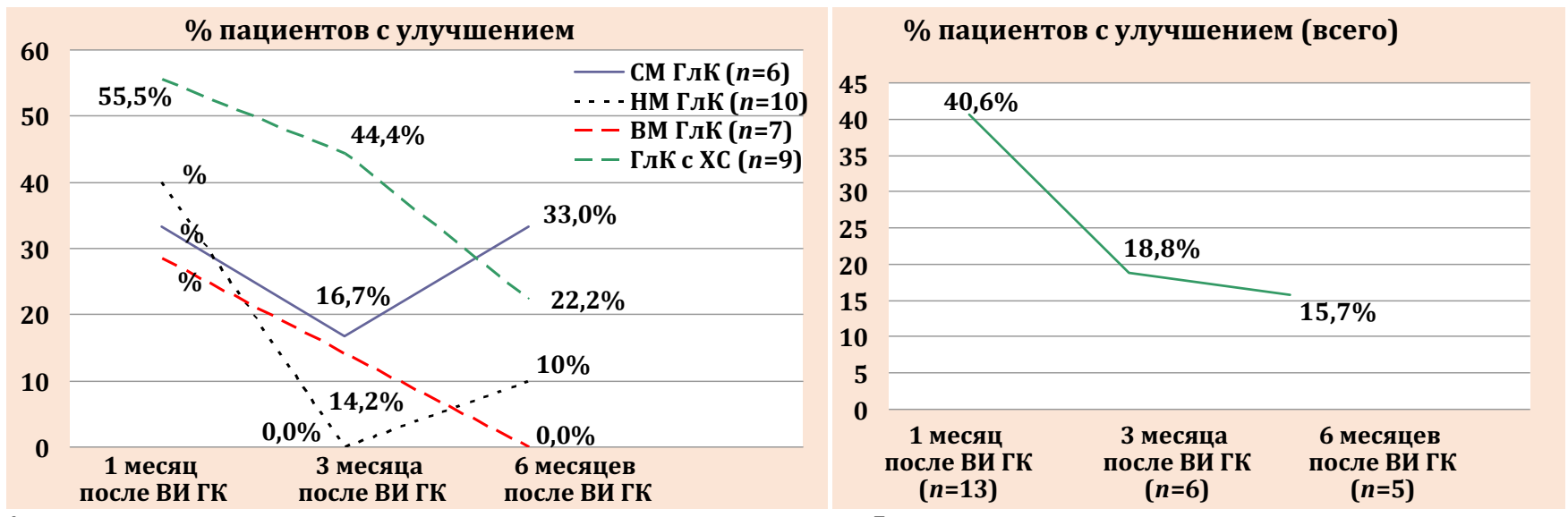

A

Рис. 11. Результаты ВИ ГлК у пациентов с III стадией ОА КС: А - изменение числа больных с улучшением в сравниваемых группах; Б - изменение общего числа больных с улучшением 
случаях. В 1 случае через 3 мес. результат улучшился с хорошего до отличного, в 1 - ухудшился до удовлетворительного. Через 6 мес. у обоих пациентов результат вновь оценивался как хороший. При использовании ВМ ГлК хороший результат через 1 мес. наблюдался у $2(28,6 \%)$, а через 3 мес. - у 1 (14,2\%) больного. Через 6 мес. улучшения не было ни в одном случае. Применение ГлК с ХС через 1 мес. позволило достичь хорошего результата в $5(55,5 \%)$ случаях. Через 3 мес. улучшение сохранялось у $4(44,4 \%)$, а через 6 - у 2 (22,2\%) больных.

\section{Обсуждение}

Известно, что по мере прогрессирования ОА эффективность консервативных методов лечения, в том числе ВИ ГлК, снижается. Так, Turajane Т. и соавт. [27] выполняли ВИ ГлК 208 пациентам с ОА КС. При I и II стадии ОА по классификации Ahlback результаты лечения были лучше, чем при III-V стадиях. В российском исследовании Г. В. Куропаткин [28] продемонстрировал, что боль после ВИ ГлК уменьшается независимо от стадии ОА КС, однако лучшие результаты были получены у пациентов с I стадией. Другие исследователи, хоть и указывают в критериях включения ОА КС I-III стадии, оценку результатов внутрисуставного введения препаратов ГлК осуществляют независимо от стадии болезни [29-31] или анализируют другие факторы, влияющие на эффективность (возраст пациентов, режим дозирования и количество инъекций препаратов ГлК, толщину хрящевой ткани суставных поверхностей КС [31-33]). Применение для изучения эффективности внутрисуставного введения препаратов ГлК при ОА КС разных критериев оценки результата приводит к значительным расхождениям заключений метаанализов: от полной неэффективности до высокой эффективности препаратов ГлК в лечении пациентов с ОА КС [18, 22-24, 34]. Столь широкий разброс выводов по данной проблеме затрудняет решение вопроса о целесообразности применения ВИ ГлК. Наше исследование является лишь малым шагом к определению места ГлК в лечении ОА КС. Полученные нами результаты показывают, что при I стадии ОА КС изученные препараты обладают высокой эффективностью. Так, в течение 1 мес. после курса ВИ все они позволяли уменьшить интенсивность боли в пораженном КС на 25-30,0 мм по ВАШ. Максимальное снижение интенсивности боли и увеличение общего счета KOOS при I стадии OA KC наблюдалось через 3 мес. после ВИ ГлК. Позднее боль постепенно усиливалась, а общий счет KOOS снижался. Тем не менее у 71,2\% пациентов улучшение, достигнутое после ВИ ГлК, сохранялось и через 6 мес.

При II стадии ОА КС внутрисуставное введение препаратов НМ, СМ ГлК и ГлК с ХС позволяет сохранить улучшение у большинства пациентов в течение 3 мес., а ВМ ГлК - около 1 мес. Через 3 мес. после курса лечения результат введения ГлК с ХС был лучше, чем в других группах. Однако через 6 мес. статистически значимых различий между исследуемыми препаратами обнаружено не было. Возможно, это обусловлено относительно небольшим числом пациентов в сравниваемых группах и целесообразно провести подобное исследование на большем клиническом материале. В целом при II стадии ОА КС внутрисуставное введение препаратов ГлК примерно в половине случаев в течение 1 мес. приводит к улучшению, частота которого после 3 мес. резко снижается и через 6 мес. после ВИ составляет около $30 \%$.

При III стадии ОА КС внутрисуставное введение НМ, СМ и ВМ ГлК позволило части пациентов добиться снижения боли в КС на 1 мес., а ГлК с ХС - до 3 мес. Большее количество пациентов с отличным и хорошим результатом лечения в группе ГлК с ХС, возможно, обусловлено низкими исходными значениями боли по сравнению с другими группами. Следует также учитывать, что больные, получавшие ГлК с ХС, были значимо моложе, чем пациенты в группах НМ и СМ ГлК. Результаты применения ВИ ГлК при III стадии ОА КС сопоставимы, но низкоэффективны. Улучшения через 1 мес. после курса лечения удалось добиться лишь у 40,6\% пациентов. При этом уже через 3 мес. их число снизилось до 18,8\%, а через 6 мес. - до 15,7\%.

\section{Выводы}

1. Внутрисуставное введение препаратов ГлК на I стадии ОА КС - высокоэффективный метод консервативного лечения, позволяющий купировать боль и улучшать функцию коленного сустава на срок до 6 мес.

2. Применение НМ и СМ ГлК, а также ГлК с ХC на II стадии ОА КС позволяет уменьшить боль на 3 мес. ВМ ГлК способствует снижению интенсивности боли на $1 \mathrm{мес.}$

3. Внутрисуставные инъекции НМ, СМ и ВМ ГлК при III стадии ОА КС приводят к снижению интенсивности боли в течение 1 мес., а ГлК с ХС позволяет уменьшить боль на срок до 3 мес.

\section{Прозрачность исследования}

Исследование не имело спонсорской поддержки. Авторы несут полную ответственность за предоставление окончательной версии рукописи в печать.

Декларация о финансовых и других взаимоотношениях

Все авторы принимали участие в разработке концепции статьи и в написании рукописи. Окончательная версия рукописи была одобрена всеми авторами. Авторы не получали гонорар за статью.

\section{СПИСОК ЛИТЕРАTУРЫ / REFERENCES}

1. Насонов Е.Л., ред. Российские клинические рекомендации. Ревматология. М.: ГЭОТАР-Медиа; 2017. 240 c. [Nasonov E.L. (ed.). Russian clinical guidelines. Rheumatology. Moscow: GEOTAR-Media; 2017. 240 p. (In Russ.)].

2. Freitag J., Bates D., Boyd R., et al. Mesenchymal stem cell therapy in the treatment of osteoarthritis: reparative pathways, safety and efficacy - a review. BMC Musculoskelet Disord. 2016;17:230. DOI: $10.1186 / \mathrm{s} 12891-016-1085-9$

3. Pereira D., Peleteiro B., Araujo J., et al. The effect of osteoarthritis definition on prevalence and incidence osteoarthritis definition on prevalence and incidence estimates: a systematic review. Osteoarthritis cartilage. 2011;19(11):1270-1285. DOI: 10.1016/j. joca.2011.08.009

4. Соловьева И.В., Стребкова Е.А., Алексеева Л.И., Мкртумян А.М. Влияние снижения массы тела на проявления остеоартроза коленных суставов. Ожирение и метабо- 
лизм. 2014;4:41-47. [Solovieva I.V., Strebkova E.A.,

Alekseeva L.I., Mkrtumyan A.M. The effect of weight loss on the manifestations of osteoarthritis of the knee joints. Ozhireniye i metabolizm $=$ Obesity and metabolism. 2014;4:41-47 (In Russ.)]. DOI: 10.14341/OMET2014441-47

5. Бадокин В.В. Остеоартроз коленного сустава: клиника, диагностика, лечение. Современная ревматология. 2013;3:70-75. [Badokin V.V. Osteoarthritis of the knee joint: clinic, diagnosis, treatment. Sovremennaya revmatologiya $=$ Modern rheumatology. 2013;3:70-75 (In Russ.)].

6. Алексеева Л.И., Зайцева Е.М. Перспективные направления терапии остеоартроза. Научно-практическая ревматология. 2014;52(3):247-250. [Alekseeva L.I., Zaitseva E.M. Promising areas of therapy for osteoarthritis. Nauchno-prakticheskaya revmatologiya $=$ Scientific and practical rheumatology. 2014;52(3):247-250 (In Russ.)].

7. Каратеев А.Е., Алексеева Л.И., Филатова Е.Г. и др. Обезболивающие препараты в терапевтической практике. М.: ООО «ИМА- ПРЕСС», 2013. 136 c. [Karateev A.Е., Alekseeva L.I., Filatova E.G. et al. Painkillers in therapeutic practice. Moscow: IMA-press, 2013. 136 p. (In Russ.)].

8. Nelson A.E., Allen K.D., Golightly Y.M., et al. A systematic review of recommendations and guidelines for the management of osteoarthritis: The chronic osteoarthritis management initiative of the U.S. bone and joint initiative. Semin Arthritis Rheum. 2014;43(6):701712. DOI: 10.1016/j.semarthrit.2013.11.012. Epub 2013.

9. Каратеев А.Е., Насонов Е.Л., Яхно Н.Н. и др. Клинические рекомендации «Рациональное применение нестероидных противовоспалительных препаратов (НПВП) в клинической практике». Современная ревматология. 2015;9(1):4-23. [Karateev A.E., Nasonov E.L., Yakhno N.N., et al. Clinical guidelines "Rational use of nonsteroidal antiinflammatory drugs (NSAIDs) in clinical practice". Sovremennaya revmatologiya $=$ Modern Rheumatology Journal. 2015;9(1):4-23 (In Russ.)]. DOI: 10.14412/1996-7012-2015-1-4-23

10. Knudson W., Loeser R.F. CD44 and integrin matrix receptors participate in cartilage homeostasis. Cel Mol Life Sci. 2002;59:36-44. DOI: 10.1007/s00018-002-8403-0

11. Smith M.M., Cake M.A., Ghosh P., et al. Significant synovial pathology in a meniscectomy model of osteoarthritis: modification by intra-articular hyaluronan therapy. Rheumatology (Oxford). 2008;47(8):1172-1178. DOI: 10.1093/ rheumatology/ken219

12. Bagga H., Burkhardt D., Sambrook P., March L. Long-term effects of intraarticular hyaluronan on synovial fluid in osteoarthritis of the knee. J Rheumatol. 2006;33(5):946-950.

13. Хабаров В.Н., Бойков П.Я., Колосов В.А., Иванов П.Л. Гиалуронан в артрологии. Комплексы гиалуроновой кислоты с низкомолекулярными биорегуляторами - новая страница в лечении суставных патологий. Под общ. ред. Хабарова В.Н. М.: ООО «Адвансед солюшнз», 2014. 208 с. [Khabarov V.N., Boikov P.Ya., Kolosov V.A., Ivanov P.L.; Khabarov V.N., editor. Gialuronan v artrologii. Kompleksy gialuronovoi kisloty s nizkomolekulyarnymi bioregulyatorami novaya stranitsa $\mathrm{v}$ lechenii sustavnykh patologii [Hyaluronan in arthrology. Hyaluronic acid complexes with low molecular weight bioregulators - a new page in the treatment of articular pathologies]. Moscow: Advansed solyushnz; 2014. 208 p. (In Russ.)]. ISBN 978-5-906722-14-0

14. Waller K.A., Zhang L.X., Fleming B.C., Jay G.D. Preventing friction-induced chondrocyte apoptosis: comparison of human synovial fluid and hylan G-F 20. J Rheumatol. 2012;39(7):14731480. DOI: 10.3899/jrheum. 111427. Epub 2012.

15. Homandberg G.A., Ummadi V., Kang H. The role of insulin-like growth factor-I in hyaluronan mediated repair of cultured cartilage explants. Inflamm Res. 2004;53(8):396-404. Epub 2004.

16. Campo G.M., Avenoso A., Nastasi G., et al. Hyaluronan reduces inflammation in experimental arthritis by modulating TLR-2 and TLR-4 cartilage expression. Biochim Biophys Acta. 2011;1812(9):1170-1181. DOI: 10.1016/ j.bbadis.2011.06.006.
17. Петухов А.И., Корнилов Н.Н., Куляба Т.А. Инъекционные препараты гиалуроновой кислоты для лечения гонартроза с позиций доказательной медицины. Научно-практическая ревматология. 2018;56(2):239-248. [Petukhov A.I.,

Kornilov N.N., Kulyaba T.A. Injectable hyaluronic acid drugs for the treatment of knee osteoarthritis in the context of evidence-based medicine. Nauchno-Prakticheskaya Revmatologiya $=$ Rheumatology Science and Practice. 2018;56(2):239-248 (In Russ.)]. DOI: 10.14412/1995-4484-2018239-248

18. Bannuru R.R., Vaysbrot E.E., Sullivan M.C., McAlindon T.E. Relative efficacy of hyaluronic acid in comparison with NSAIDs for knee osteoarthritis: a systematic review and meta-analysis. Semin Arthritis Rheum. 2014;43(5):593-599.

DOI: $10.1016 /$ j.semarthrit.2013.10.002.

19. Colen S., van den Bekerom M.P., Mulier M., Haverkamp D. Hyaluronic acid in the treatment of knee osteoarthritis: a systematic review and meta-analysis with emphasis on the efficacy of different products. BioDrugs.2012 Aug 1;26(4):257268. DOI: $10.2165 / 11632580-000000000-00000$

20. Bruyere O., Burlet N., Delmas P.D., et al. Evaluation of symptomatic slow-acting drugs in osteoarthritis using the GRADE system. BMC Musculoskelet Disord. 2008;9:165. DOI: $10.1186 / 1471-2474-9-165$

21. Divine J.G., Zazulak B.T., Hewett T.E. Viscosupplementation for knee osteoarthritis: a systematic review. Clin Orthop Relat Res. 2007;455:113-122.

22. Bannuru R.R., Natov N.S., Dasi U.R., et al. Therapeutic trajectory following intraarticular hyaluronic acid injection in knee osteoarthritis - meta-analysis. Osteoarthritis Cartilage. 2011;19(6):611-619. DOI: 10.1016/j.joca.2010.09.014. Epub 2011.

23. Jevsevar D., Donnelly P., Brown G.A., Cummins D.S. Viscosupplementation for Osteoarthritis of the Knee: A Systematic Review of the Evidence. J Bone Joint Surg Am. 2015;97(24):2047-2060. DOI: 10.2106/JBJS.N.00743

24. Pai S.K., Allgar V., Giannoudis P.V. Are intra-articular injections of Hylan G-F 20 efficacious in painful osteoarthritis of the knee? A systematic review \& meta-analysis. Int J Clin Pract. 2014;68(8):1041-1047. DOI: 10.1111/ijcp.12430. Epub 2014 May 5.

25. Kolasinski Sh.L., Neogi T., Hochberg M.C., et al. 2019 American College of Rheumatology/Arthritis Foundation Guideline for the Management of Osteoarthritis of the Hand, Hip, and Knee. Arthritis Care \& Research. 2020;72(2):149-162. DOI: 10.1002/ acr.24131

26. Bannuru R.R., Osani M.C., Vaysbrot E.E., et al. OARSI guidelines for the non-surgical management of knee, hip, and polyarticular osteoarthritis. Osteoarthritis and Cartilage. 2019. DOI: 10.1016/j.joca.2019.06.011

27. Turajane T., Tanavaree A., Labpiboonpong V., Maungsiri S. Outcomes of Intra-Articular Injection of Sodium Hyaluronate for the Treatment of Osteoarthritis of the Knee. J Med Assoc Thai. 2007;90(9):1845-1852.

28. Куропаткин Г.В. Оценка применения Гилана gF-20 у пациентов с остеоартрозом коленного сустава (предварительные результаты). Травматология и ортопедия России. 2016;22(3):79-87. [Kuropatkin G.V. Evaluation of safety and effectiveness of Hylan GF-20 in patients with knee osteoarthritis in real life practice: preliminary results]. Travmatologia i ortopedia Rossii $=$ Traumatology and Orthopedics of Russia. 2016;22(3):79-87 (In Russ.)]. DOI: 10.21823/2311-2905-2016-223-79-87

29. Berenbaum F., Grifka J., Cazzaniga S., et al. A randomised, double-blind, controlled trial comparing two intraarticular hyaluronic acid preparations differing by their molecular weight in symptomatic knee osteoarthritis. Annals of the Rheumatic Diseases. 2012;71(9):1454-1460. DOI: 10.1136/annrheumdis-2011-200972

30. Ризоева О.Р., Саидов Е.У., Махмудов Х.Р. Сравнительная клинико-лабораторная и инструментальная оценка эффективности моно- и комбинированной терапии терафлексом с остени- 
лом у больных первичным остеоартритом коленных суставов. Вестник Авиценны. 2019;21(4):610-617. [Rizoeva O.R.,

Saidov Yo.U., Makhmudov Kh.R. [Comparative clinical laboratory and instrumental assessment of effectiveness of mono- and combined therapy of Teraflex with Ostenile in patients with primary knee osteoarthritis]. Vestnik Avitsenny $=$ Avicenna Bulletin. 2019;21(4):610-7. (In Russ.)]. DOI: 10.25005/2074-0581-201921-4-610-617

31. Ricci M., Micheloni G.M., Berti M., et al. Clinical comparison of oral administration and viscosupplementation of hyaluronic acid (HA) in early knee osteoarthritis. Musculoskeletal surgery. 2016;101(1):45-49. DOI: 10.1007/s12306-016-0428-x

Бялик В. E. ORCID: https://orcid.org/0000-0002-3745-0924

Макаров M. A. ORCID: https://orcid.org/0000-0002-56267404

Бялик Е. И. ORCID: https://orcid.org/0000-0001-7938-1536

Макаров С. A. ORCID: $h$ ttps://orcid.org/0000-0001-8563-0631

Нестеренко В. A. ORCID: https://orcid.org/0000-0002-7179-8174

Нурмухаметов M. P. ORCID: https://orcid.org/0000-0001-6847-6396
32. McElheny K., Toresdahl B., Ling D., et al. Comparative Effectiveness of Alternative Dosing Regimens of Hyaluronic Acid Injections for Knee Osteoarthritis: A Systematic Review. Sports Health: A Multidisciplinary Approach, 2019;11(5):461-466. DOI: $10.1177 / 1941738119861545$

33. Henrotin Y., Bannuru R., Malaise M., et al. Hyaluronan derivative HYMOVIS ${ }^{\circledR}$ increases cartilage volume and type ii collagen turnover in osteoarhritic knee: data from MOKHA study. BMC Musculoskeletal Disorders, 2019; 20(1). DOI: 10.1186/s12891-019-2667-0.

34. Vannabouathong C., Bhandari M., Bedi A., et al. Nonoperative Treatments for Knee Osteoarthritis. Jbjs Reviews. 2018;6(7):e5. DOI: 10.2106/JB JS.RVW.17.00167 